\title{
Entre Revolución y Restauración: El Estado Comercial Cerrado de J. G. Fichte
}

Jorge Prendas Solano

\section{OpenEdition}

Journals

Edición electrónica

URL: http://journals.openedition.org/ref/459

DOI: $10.4000 /$ ref.459

ISSN: 2258-014X

Editor

EuroPhilosophie Editions

Referencia electrónica

Jorge Prendas Solano, «Entre Revolución y Restauración: El Estado Comercial Cerrado de J. G. Fichte », Revista de Estud(i)os sobre Fichte [En línea], 7 | 2013, Publicado el 30 diciembre 2013, consultado el 08 septiembre 2020. URL : http://journals.openedition.org/ref/459 ; DOI : https://doi.org/10.4000/ref.459

Este documento fue generado automáticamente el 8 septiembre 2020.

(c) EuroPhilosophie 


\title{
Entre Revolución y Restauración: El Estado Comercial Cerrado de J. G. Fichte
}

\author{
Jorge Prendas Solano
}

\begin{abstract}
A Roberto Fragomeno, viajero incansable en los terrenos de la gran filosofía alemana.
\end{abstract}

\section{Introducción}

1 Uno de los temas clásicos de la filosofía política moderna que suele ser puesto a discusión es la cuestión central del Estado y sus intrincadas relaciones tanto con el entramado social como con la idea de nación. Dentro del (así llamado) idealismo alemán la filosofía política de J.G. Fichte representa una importante muestra del esfuerzo por recuperar y al mismo tiempo dar sentido a la cuestión del Estado y su particular posición dentro de la sociedad. Esta empresa político filosófica viene ciertamente unida al proyecto fichteano de (re-)construir una identidad nacional alemana.

El pensamiento político fichteano es sin duda alguna uno de los momentos más importantes de la filosofía clásica alemana, y sin embargo continúa siendo paradójicamente un autor poco frecuentado en los estudios sobre filosofía clásica alemana y filosofía política. La justificación de ello puede situarse en dos razones de distinta naturaleza. Primero, la posición de Fichte dentro del idealismo alemán: Fichte es un autor atrapado a la sombra de dos colosos del pensamiento como Kant y Hegel. Pero además existe una segunda razón del descuido en el que ha recaído el pensamiento de Fichte, y esto tiene relación directa con la complejidad de su obra, la cual se articula como una narración de una profundidad conceptual a la que el lector de filosofía no suele estar acostumbrado. 
3 En este trabajo se pretende un análisis riguroso de un momento específico de la obra política de Fichte, me refiero a su escrito sobre el Estado comercial cerrado de 1800 (Der geschlossene Handelsstaat, de aquí en más gHS). Por esto creo necesario, antes de iniciar mi análisis, hacer una consideración sobre la evolución del pensamiento político de este autor. Se trata de una progresiva evolución marcada por una serie de motivos de carácter histórico y biográfico. No se trata, pues, de una evolución que responda únicamente a criterios de orden académico, sino a una serie de circunstancias mucho más complejas que rodean la obra de Fichte.

4 Así pues, está bien claro que las teorías políticas fichteanas pueden ser divididas al menos en dos etapas, un primer momento caracterizado por el libro escrito por Fichte antes de incorporarse al claustro académico de la Universidad de Jena: Contribuciones para la rectificación del juicio del Público sobre la Revolución francesa de 1793, y un segundo momento iniciado con la publicación de su doctrina del derecho natural (GNR) de 1796/97 y que encuentra en El Estado comercial Cerrado ( $g \mathrm{HS}$ ) de 1800, ${ }^{1}$ libro redactado luego de abandonar la Universidad de Jena a raíz de la polémica del ateísmo, uno de sus puntos más claros de concreción. Mientras en el primer periodo Fichte articula su discurso exclusivamente desde la visión del oprimido sin tener en cuenta el ámbito de las instituciones, en el segundo periodo busca diseñar instituciones que puedan hacer realidad la emancipación del género humano que, según Fichte, es un imperativo para todo ser racional.

5 De esta manera, el objetivo del presente artículo consiste en reconstruir el hilo del planteamiento fichteano alrededor de su texto del Estado Comercial Cerrado, que se convierte en la piedra angular de la filosofía política de Fichte en su etapa posterior a Jena, la cual corresponde con un momento socio-histórico de transición hacia una nueva época caracterizada por el agotamiento de las energías utópicas y la eventual aparición de un contexto mucho más conservador en el plano político.

\section{La concepción política fichteana en el Estado Comercial Cerrado}

6 De acuerdo a Franco Barrio el idealismo fichteano se presenta como un intento de introducción de la razón en la historia. ${ }^{2}$ Efectivamente esto es así, en la medida en que el gHS presenta un intento por construir racionalidad en el ámbito socio-económicopolítico de la interacción humana. Para apreciar la dimensión del proceso racionalizador que Fichte lleva a cabo, basta con prestar atención al tono de la discusión planteada por Fichte respecto del papel cumplido por el Estado en la sociedad, la economía y la política, y al mismo tiempo la enorme importancia que asigna a la idea de un Estado racional como potencia ordenadora y creadora (predicados que recuerdan la descripción del Yo absoluto del Fundamento de toda la Doctrina de la Ciencia de 1794/95). ${ }^{3}$

7 Con respecto a este punto, se vuelve necesario señalar que en su calidad de interlocutor del kantismo (propiamente en el espíritu, y no en la letra menuda), Fichte nunca abandonó la idea reguladora del primado de la razón práctica (piedra angular del criticismo kantiano), cosa que es evidente y posible de verificarse en el escrito temprano Ensayo de una crítica de toda revelación (1792), o en la mencionada GWL. Junto con esto, es necesario señalar que el desarrollo mismo de la filosofía política de Fichte 
se encuentra mediada por los principios epistemológicos (no necesariamente metafísicos), de su doctrina de la ciencia. Es decir, existe un correlato solidario entre el planteamiento que le da luz al nacimiento del Yo Absoluto, incondicionado y productor de sí mismo con el planteamiento del Estado plenamente autodeterminado, autárquico y autosuficiente del $g H S .4$

8 Una pequeña muestra de lo anterior es la consideración precisa que asocia la esfera de dominio de la política con el dominio del ámbito especulativo del filósofo. Desde el planteamiento del $g H S$, no existe espacio para la separación entre una filosofía considerada como episteme (exploración de los orígenes de la interacción entre el Yo y el No-Yo en cuanto sujeto y objetos teóricos), ${ }^{5}$ y la práctica de la política en el sentido demostrado por su GNR de 1796/97. ${ }^{6}$

En la concepción del $g H S$, la praxis política fichteana implica la aplicación de una regla general a cada caso particular, desde luego de forma diferenciada puesto que cada particular presenta sus propios elementos. Bajo esta forma, el centro de la propuesta del texto en cuestión consiste en la creación de un Estado comercial y jurídicamente cerrado. Este proceso debe darse, según Fichte, entre otras medidas, a través de la supresión de la moneda mundial y la introducción de una moneda nacional que resuelva las necesidades del proceso de producción en el ámbito interno del Estado, sin necesidad de recurrir al concurso o auxilio de un Estado extranjero.

10 Un primer asunto digno de ser explorado es el concerniente a la concepción sobre la misión del Estado. En este punto, Fichte no deja duda alguna en el inicio de su gHS:

[...] yo diría que es misión del Estado, en primer lugar, dar a cada uno lo suyo, ponerlo en su propiedad y, solo después, protegerlo también. ${ }^{7}$

11 Por lo tanto, se puede derivar de lo anterior que para el Estado cumplir el rol de dar a cada quién lo que le corresponde es necesario cerrar toda posibilidad de intercambio comercial entre los individuos. En lo siguiente daremos desarrollo a esta cuestión.

\section{La propiedad privada y su relación con la acción del Estado}

12 Ahora bien, resulta muy importante considerar lo relacionado a la teoría de Fichte sobre el Estado y el origen de la propiedad privada. La posición del filósofo resulta ser bien clara, adhiriendo a una fuerte postura anti-liberal donde lo que define al ser humano no es su posesión o el mantenimiento de la propiedad, pues en todo caso la propiedad sólo es el resultado de un pacto social, de un acuerdo común que se realiza entre todos los individuos, donde el reconocimiento mutuo e intersubjetivo es la clave del consenso. Sin reconocimiento, sin renuncia de todos al objeto, nadie puede apropiarse del mismo. ${ }^{8}$

Originariamente todos tienen el mismo derecho a todo, es decir, ningún individuo posee de antemano el más mínimo derecho respecto de otro. Sólo mediante la renuncia de todos a una cosa concreta, como consecuencia del deseo de guardarla para mí, ésta se convierte en propiedad mía. ${ }^{9}$

14 En esta línea, resulta fundamental resaltar que el derecho de propiedad para Fichte no aparece como el derecho de acceso a la variedad de las cosas empíricas; sino más bien originariamente como un derecho de acciones. Son precisamente las acciones, las interacciones entre los sujetos las que provocan el conflicto social, el choque entre las 
acciones libres de los individuos, lo cual no existiría si todos los sujetos fueran pasivos. Es únicamente en medio de la existencia social donde se determina el conflicto, y es en la tensión social donde se habilita la posibilidad de la existencia de lo privado como expresión de la colectividad.

En otras palabras, lo importante no es definir qué cosa pertenece a quién, lo cual sería abstracto, sino más bien circunscribir el ámbito de acción de cada uno de los individuos, de manera tal que esté claro cuál es el campo de su libre acción. En este punto, Fichte reconoce que la propiedad es un pacto producto del reconocimiento de los sujetos, un intercambio simbólico que significa reconocer al otro y su acción para posteriormente reconocer su derecho sobre los objetos o cosas. Un derecho sobre las cosas que no puede traducirse como una tendencia infinita, pues para Fichte el tema de la cantidad de propiedad de la cual gozan los sujetos sí resulta central dentro de la discusión ético-política. El Estado no puede permitir bajo ningún concepto, que la propiedad sea indefinida pues ello supondría un perjuicio o seria amenaza para la convivencia social. De lo que se trata es que todos los individuos gocen de las condiciones mínimas como para conseguir el acceso a una vida digna y libre de la menesterosidad absoluta, es decir, huir a la situación de necesidad extrema que elimina la posibilidad de construirse como sujeto moral autónomo. Según Fichte, es un absurdo que el Estado permanezca neutral frente las necesidades de los individuos, y más aún que se mantenga en una condición indiferente respecto de la distribución de la propiedad:

16 La finalidad del Estado real, el cual se aproxima mediante su habilidad a la razón, tiene que ser la de proporcionar paulatinamente a cada uno lo suyo, en el sentido de la palabra que acabamos de indicar. ${ }^{10}$

17 La convivencia social está atravesada por la actividad del Estado que se convierte en un garante de la distribución de la propiedad para efectos de que los individuos puedan vivir sin riesgos, teniendo a su mano lo básico. Es por ello que Fichte defiende con vehemencia absoluta que carece de racionalidad el que alguien pueda gastar de manera desmedida en lo superfluo sin recordar que en el mismo momento permanecen personas con carencias elementales. No es asunto de tener el capital o no; aun cuando se tenga es contrario al progreso moral derrochar cuando hay necesidades apremiantes en mis conciudadanos:

18 En primer lugar, todos los ciudadanos deben estar saciados y vivir seguros, antes que alguien decore su vivienda; en primer lugar, todos deben estar vestidos de una forma decente y abrigadas antes que alguien se vista de manera lujosa. ${ }^{11}$

De esta manera, Fichte concibe una función muy concreta a su visión de Estado, y esta tesis recorre enteramente todo el pensamiento vertido en el texto del $g H S$, en contraste con lo que podrían sostener otras tradiciones de filosofía política como el liberalismo. La institución estatal no consiste en un mero árbitro que se encarga de juzgar el orden dado de las cosas; ni siquiera se trata tampoco de un simple mediador en medio del conflicto o un gendarme de la propiedad privada, sino que la finalidad del aparato estatal es dar a cada cual paulatinamente lo suyo, y para cumplir con esa funcionalidad debe existir un cierre comercial del Estado con respecto a todo sujeto externo, sean individuos de otros Estados, sean estos Estados mismos. Es por esta razón que al Estado fichteano no le es nunca indiferente el tejido social. ${ }^{12}$ Se sabe como central dentro la organización social y por eso su carácter deber ser la autonomía, ejerciendo funciones esenciales como limitar, controlar y colocar orden en el espacio público. En este 
sentido, no existe espacio para el anarquismo en las tesis de filosofía política que se desprenden a partir del $g H S$, puesto que lo central consiste en el fortalecimiento de las capacidades del aparato estatal para controlar asuntos tan variados como la división del trabajo o cuestiones mucho más complejas como el comercio entre los individuos de una misma sociedad.

Este asunto anterior se ve reflejado, por ejemplo, en el tratamiento que hace Fichte respecto del origen de la propiedad privada. Cuando se trata de discutir el interés de los individuos, este interés siempre se encuentra sobrecogido por el bienestar del colectivo social, y no de la individualidad aislada y encogida sobre sí misma. Por esa razón, como decíamos antes, es incorrecto defender o tolerar desde el Estado la posesión de dinero para adquirir lo superfluo cuando deben solucionarse necesidades básicas de los individuos. Aunado a lo anterior, hay un asunto crucial de destacar en el planteamiento de Fichte respecto de la propiedad privada. En polémica con el liberalismo económico, el filósofo alemán señala que la propiedad no es una especie de acto originario; ni tampoco se trata de una cuestión consustancial a la naturaleza humana. De hecho, el problema más importante asociado a la propiedad no es el de qué o cuál objeto le corresponde a cada quién, sino más bien que el Estado debe antes de cualquier cosa establecer los límites de las acciones para cada individuo, lo cual habilita posteriormente un pacto de reconocimiento que lleva a los sujetos a saber que sólo puede haber lo privado en medio del reconocimiento intersubjetivo:

A mi modo de ver, el error fundamental de las teorías de la propiedad opuestas a la mía, la primera fuente de donde fluyen todas las afirmaciones falsas sobre ella, el verdadero motivo de la oscuridad y de la sutileza de algunas doctrinas, la verdadera causa de la parcialidad y del carácter incompleto para su aplicación en la vida real, consiste en esto: en poner la propiedad primaria y originaria en la posesión exclusiva de una cosa. ${ }^{13}$

Insistimos sobre este punto. La originalidad y radicalidad del planteamiento de Fichte es evidente. Se trata de una teoría que coloca como fundamento de la propiedad primaria y originaria una determinada actividad libre. Fichte no apela a un supuesto carácter natural de la propiedad, sino que la operación intelectual consiste en una historización de los orígenes de lo privado. Esto habla de un principio metodológico de los idealistas alemanes: fuera de la comprensión histórica no se puede comprender los orígenes de algo. Comprender el problema significa siempre comprender la historia del problema.

\section{El cierre del Estado Comercial}

El proceso de cierre o clausura comercial (esencial para la constitución de un Estado autónomo y autodeterminado en clave fichteana) consiste en un paulatino tránsito desde una economía abierta hasta la clausura total del comercio exterior. La dinámica de realización de este proceso viene determinada a partir de un conjunto de medidas elementales que deben aplicarse en un primer momento y otras cuya aplicación es pensada en el largo plazo. Por ejemplo, es determinante que en el momento del inicio de la clausura del sistema de comercio el ciudadano que participa del comercio mundial tenga el derecho a disfrutar de lo que antes podía adquirir libremente. Esto por una razón sencilla: no se puede colocar en una situación de indefensión al ciudadano. Aquí se advierte algo elemental en el planteamiento de nuestro filósofo, a saber, que en la clausura del Estado comercial el Estado, según Fichte, no debe caer en arbitrariedades 
en su acción de conseguir la esencial autarquía política. Más bien, el aparato estatal debe esmerarse en sentar las condiciones de posibilidad para que los ciudadanos no se sientan desprotegidos frente a la situación que provoca la clausura comercial. Es por ello que el cierre comercial no se hace de inmediato, sino que sigue una lógica interna y progresiva que de manera ascendente elimina el comercio exterior y lo sustituye por el nacional.

Por ello mismo, Fichte insiste en la necesidad de conseguir desplegar los elementos básicos sobre los cuales sea posible el bienestar general sin causar un trastorno general y profundo sobre la vida de los individuos de un Estado. Así pues el gobierno debe fomentar y procurar la fabricación nacional de todas las manufacturas necesarias para sus ciudadanos, de modo que quede anulada toda posibilidad de incertidumbre entre la población. La clausura del Estado comercial no consiste, ciertamente, en una renuncia drástica, sino paulatina, a productos básicos o elementales provenientes del extranjero que sean necesarios para la supervivencia de los ciudadanos.

En medio de estas consideraciones, Fichte introduce un elemento capital para ser tomado en cuenta dado su carácter polémico. Fichte sostiene que para que el Estado pueda cerrar sus fronteras comerciales es necesario que lo haga de la misma manera con sus fronteras naturales. Sin embargo, el cierre de fronteras no implica la idea de despojar a los extranjeros de sus tierras, o promover una política de carácter xenófobo contra los inmigrantes. Al contrario, para Fichte los extranjeros tienen todo el derecho a permanecer una vez que se realice la clausura comercial del Estado e inclusive es factible que los extranjeros que deseen obtener nacionalidad lo puedan realizar. El cierre de las fronteras naturales es el paso decisivo y solidario que acompaña el elemento de la clausura comercial. Ambas cosas se reclaman mutuamente en un sentido básico, dado que las fronteras naturales son el límite normal donde se termina la soberanía plena del Estado, entonces esto implica que el Estado no podrá ejercer su soberanía más allá de sus fronteras naturales (acaso un mensaje que previene eventuales deseos expansionistas), y solamente ejercerá su control dentro de las fronteras constituidas.

Respecto de este punto hay dos asuntos centrales que acotar. Primero, el tema de la constitución de las fronteras naturales es un tema espinoso por cuanto implica al mismo tiempo la consideración de la guerra. No existe en Fichte una posición elogiosa respecto del conflicto; sin embargo tampoco hay un lamento por su existencia como si de algo innecesario se tratase. La consideración es básica: la guerra es el medio por el cual los Estados consiguen establecer sus fronteras, ya que ello no se puede hacer mediante el recurso de la diplomacia u otros medios, y en esta medida la lucha entre los Estados es, a los ojos de Fichte, ineluctable.

En segundo lugar, el tema consiste en que una vez que los Estados consiguen mediante el recurso de la guerra definir sus límites ya tienen lo que racionalmente deben tener, y cualquier otra cosa está de más. El medio de la guerra se agota en el mismo momento en que las fronteras naturales están definidas para los Estados. Creo necesario insistir en este punto: no existe una postura belicista o imperialista en este aspecto del pensamiento político fichteano, más bien todo lo contrario. El problema del imperialismo o de las políticas expansionistas de los Estados emerge de la condición de que son comercialmente abiertos y deben necesariamente salir a colocar sus productos en los mercados extranjeros. La única manera en que el aparato estatal pueda garantizar su carácter no expansionista hacia otros Estados es que se cierre en términos 
comerciales. Si lo hace bien, entonces el cierre comercial fomentará o se encargará de crear buenas relaciones entre los Estados, y se volverá superfluo el interés por un crecimiento más allá de las fronteras naturales establecidas. Un Estado comercial abierto, por el contrario, se encuentra permanentemente movido por su propia dinámica interna a la necesidad de invadir nuevos territorios y movilizar sus tropas para poseer las riquezas externas:

Un Estado que sigue el sistema comercial usual y se propone conseguir cierta preponderancia en el comercio mundial, conserva un interés constante por crecer incluso fuera de sus fronteras naturales, para de este modo aumentar su comercio y, por medio del mismo, su riqueza; utilizará de nuevo a esta última para nuevas conquistas, que tendrán el mismo objetivo que las anteriores. A cada uno de estos males le pisa los talones otro, y la codicia de semejante Estado no conoce límites. ${ }^{14}$

El otro momento que complementa el cierre del Estado comercial, recordemos que es fundamental que la clausura se lleve a cabo mediante un paulatino trabajo, es procurar a la nación una independencia de los países extranjeros, en una situación bajo la cual no existan necesidades elementales entre los ciudadanos, sino más bien una condición del mayor bienestar posible. Para ello, el gobierno debe acudir al recurso de la moneda mundial como eje que permita gestionar una serie de políticas orientadas al bien común y a la obtención de las capacidades mínimas para evitar problemas de ausencia de los productos elementales. En esta medida, el gobierno debe conseguir en el extranjero la mayor cantidad de fuerza laboral y de recursos que le sea posible, así como inclusive algunas máquinas para crear una sociedad comercialmente autosuficiente:

[El gobierno] traerá, cueste lo que cueste, del extranjero grandes talentos en ciencias aplicadas, químicos, físicos, mecánicos, técnicos y fabricantes creativos. [...] Se comprarán máquinas extranjeras para copiarlas en el propio país. ${ }^{15}$

Un asunto importante de considerar es si el cierre del Estado en su actividad comercial implica una eventual clausura en otras esferas de la actividad estatal. Nada parece indicar en el texto de Fichte algo semejante. No existe en el planteo fichteano una clausura política, artístico-cultural o migratoria. La única clausura cuyo carácter es imperativo se da en el plano comercial y espacial, puesto que sin clausura comercial y cierre permanente de las fronteras naturales no puede existir plena soberanía y autodeterminación del Estado moderno. En el sentido de estimular la interacción intelectual y cultural con otros pueblos, Fichte considera necesario que el Estado estimule el derecho a viajar entre los intelectuales y ciertos técnicos de rango superior. Este intercambio no solamente es saludable, sino que además es muy necesario por cuanto estos intercambios redundan, según Fichte, en beneficio para la humanidad entera. Lo que no debe permitirse, por el otro lado, es que la "ociosa curiosidad" sea libre. Fichte no era, por cierto, nada proclive al turismo ocioso:

El derecho a viajar por fuera de un Estado comercial cerrado está reservado para los intelectuales y para los técnicos de rango superior; ya no se permitirá a la ociosa curiosidad ni al afán de diversión llevar de un lado para otro su aburrimiento por todos los países. ${ }^{16}$ 


\section{A modo de conclusión}

Es notable el tono de optimismo que invade todo el cierre del $g H S$ de Fichte. Incluso no sería erróneo afirmar que Fichte simpatiza brevemente con la idea kantiana de la paz perpetua, conseguida ésta mediante el mecanismo de la clausura del Estado comercial. Aún más, parece que se amplía la propia tesis kantiana de la paz perpetua al considerar que ésta sólo es alcanzable en la medida en que los Estados se cierren comercialmente, caso contrario privará una situación de guerra y de tensiones geopolíticas entre las naciones:

Después de que se haya universalizado este sistema, y que se haya establecido la paz perpetua entre los pueblos, ningún Estado de la superficie de la tierra tendrá el más mínimo interés en ocultar a otro sus descubrimientos, puesto que cada uno podrá utilizarlos sólo en su interior y para sí mismo, pero de ningún modo para oprimir a otros y conseguir predominio sobre ellos. ${ }^{17}$

No tiene sentido pensar desde la lógica discursiva que recorre estas palabras, cómo un Estado tendría interés en invadir a otro o ejercer control sobre territorios extranjeros si los Estados del mundo estuvieran comercialmente cerrados. En este punto, el filósofo alemán acierta notablemente cuando realiza un diagnóstico de las diversas políticas imperialistas de los Estados europeos de la época (desde el siglo XV en adelante), plenamente envueltos en políticas de captura de territorios extranjeros y sumisión de sus ciudadanos.

De esta situación, los latinoamericanos sabemos perfectamente. Sin la brutal colonización de los territorios de América Latina no hubiese sido posible el despliegue de la modernidad europea, misma que se asienta en la desmedida pretensión mercantil de crear colonias en el extranjero desde las cuales extraer los recursos necesarios para que luego sean trasladados a las grandes metrópolis. Este es el mejor de los ejemplos históricos para reafirmar la posición política fichteana, a saber, la apertura comercial redunda en políticas colonizadoras e imperialistas, acompañado con la presencia de prácticas genocidas.

\section{Bibliografía utilizada}

Acosta, E., (2009) "Vier Bestimmungen des Nicht-Ich in der Jenenser Periode der Fichteschen Wissenschaftslehre", en: Pfeiffer, M. \& Rapic, S. (eds.) Das Selbst und sein Anderes: Festschrift für Klaus Erich Kaehler, München: Alber, pp.98-108.

Arrese Igor, H., (2010) "El derecho de coacción como garantía del equilibrio del derecho", en: Acosta, E. (ed.) Revista de Estudios sobre Fichte I, pp. 69-89.

Gaudio, M. (2010), "El estado natural del hombre es el Estado", en: Acosta, E. (ed.), Revista de Estudios sobre Fichte I, pp. 33-68.

Fichte, J.G., (1991) El Estado comercial cerrado. Trad. de J. Franco Barrio. Tecnos: Madrid.

Fichte, J.G., (1975) Fundamento entero de la Doctrina de la Ciencia. Trad. de J. Cruz Cruz. Buenos Aires: Aguilar.

Franco Barrio, J., (1991) "Estudio Preliminar", en: Fichte, J. G., El Estado Comercial Cerrado. Madrid: Tecnos, pp. IX-XXXII. 


\section{NOTAS}

1. Citaré esta obra a partir de la traducción de Jaime Franco Barrio (ver bibliografía). Daré además la ubicación de cada pasaje en la edición crítica de la Academia Bávara de las Ciencias (GA).

2. Franco Barrio 1991: IX.

3. GWL, GA I/2, 255, 262 y 396.

4. Franco Barrio 1991: XIII.

5. Acosta 2009: 105-106.

6. cf. GNR, GA I/3, 329/403 §§ 1-8.

7. Fichte 1991: 16/gHS, GA I/7, 399.

8. Arrese 2010: 76, Gaudio 2010: 37-42.

9. Fichte 1991: 17/gHS, GA I/7, 54.

10. Fichte 1991: 20/gHS, GA I/7, 403.

11. Fichte 1991: 28/ gHS, GA I/7, 409.

12. Gaudio 2010: 54 .

13. Fichte 1991: 70/gHS, GA I/7, 85.

14. Fichte 1991: 126/gHS, GA I/7, 119.

15. Fichte 1991:147/gHS, GA I/7, 132.

16. Fichte 1991: 155/gHS, GA I/7, 137.

17. Fichte1991:163/gHS, GA I/7, 141.

\section{RESÚMENES}

In this paper I offer an analysis of some points to my view essential for understanding Fichte's political thought. I mainly focus on the role of the state, the deduction of property and the proposed project of the closure of the commercial state. As a conclusion I present a brief consideration related to the political and economical history of Latin-America, which I think, can open new ways in the Fichte-Scholarship.

ÍNDICE

Keywords: Fichte, economy, The Closed Commercial State

\section{AUTOR}

\section{JORGE PRENDAS SOLANO}

Instituto Tecnológico de Costa Rica / Universidad de Costa Rica 